\title{
COVID-19: the virus in the control of culture?
}

\author{
Lincoln Lopes Ferreira ${ }^{1}$ \\ Antonio Carlos P. Chagas ${ }^{2}$ \\ (iD) Wanderley M. Bernardo 3
}

1. Presidente da Associação Médica Brasileira, São Paulo, SP, Brasil 2. Diretor Científico da Associação Médica Brasileira, São Paulo, SP, Brasil 3. Coordenador do Programa Diretrizes da Associação Médica Brasileira, São Paulo, SP, Brasil

Much has been written and published about COVID19. There are more than 5,000 works within the past 3 months, varying in themes like etiology, diagnosis, treatment and prognosis, with many more still to be published $^{1-15}$.

There are countless estimates and predictions on viral progression, whether related to the doubling rate (e.g. 2.5 times per patient), multiplication factors (e.g. 23), indirect calculations based on mortality (e.g. 1\%), or even the association of all these factors, leading to corrections in the number of reported cases in the order of 6 , up to 80 times, called by some as optimistic or pessimistic.

The equal adjustment of lethality and mortality rates has occupied the time of many mathematicians, statisticians, epidemiologists and health professionals, in an attempt to contribute to decision making of the system.

There're several discussions about horizontal or vertical lockdowns, social distancing (varying from 1 to 7.5 meters), types of masks for asymptomatic patients (cloth, medical or surgical), masks for sick patients (medical or surgical), and morbidities that increase the risk of severity.

It has been discussed which individual protection materials health professionals should use (e.g., N95 masks), and regarding the hospital care process, which structural changes are necessary, due to the increased demand in the Intensive Care Unit (ICU) and hospitalization of patients with COVID-19.

We have heard national and global reports on the difficulty of processing diagnostic tests (e.g. RT-PCR) to effectively identify cases, leading to a point where, most emergency services do not investigate patients with mild symptoms of upper respiratory infection, advising them to return if symptoms worsen. Thus, the identification of COVID-19 cases has been done superficially and is limited to symptomatic cases with signs of severity.

Most global health systems have been overloaded with an unmanageable overflow, creating direct impact on mortality, while feeding into a cycle that impedes the possibility of any organized action in order to administer the local epidemic.

In the search for treatment many opted in, dropped out, opted in again, and dropped out once more, within just a few weeks, as part of an endless and exhausting media dance, whose main objective is clearly the search for solutions; but perhaps desperate and oftenly irresponsible, producing more damage than benefit. 
To make matters worse, patients with other "nonCOVID" diseases have been naturally neglected, allowing their conditions to unjustly aggravate, consequently increasing the systems inefficiency and amount of damage.

These negative experiences are striking, and invariably make us forget about successful initiatives (as such seen in South Korea), holding our attention to an indifferent view: "The same will inevitably happen here"; or perhaps romantic: "Let's go resist this small microorganism, we are bigger than THAT".

Up to this point in our reflection, you must be thinking: "I know all of this, and not just me, but everyone knows all of it. What's the point? What's the matter in here? Am I reading yet another article that says a lot but makes no recommendations? Is this article an end in itself?

You are almost right. In fact, our approach here focuses on three (3) slightly more critical aspects and, therefore, may (or may not) be considered in our decision-making strategies:

1. Epidemics are not controlled acutely and exclusively by cultural changes. Those "without knowledge" or perhaps "without appropriate education" should not hold themselves responsible for the consequences, without the opportunity and time to learn in advance. This is like an aggressive agent (in this case, the virus) who blames the victim (patient) for its consequences (death) in themselves (population). To the least, this is an unjust concept - characteristic of an impotent and incompetent system - which should be educating, protecting and caring for those under one's responsibility;

2. Sick cases (asymptomatic or not) should not be broken down into home "clusters", and here is a natural and non-medical example: this is like dividing the sections in a wildfire into small new sections, which will expand into new fires, and so on. Wildfire is fought with a holistic approach, by locating the focal points, working your way in until the fire sections are extinguished - because you can hide the cases, but you cannot hide the deaths. The inter-cluster transmission is reduced, but the intra-cluster transmission will continue to feed in new cases. The attitude to wait and see what happens without any scientific strategy, is easy, and again transfers the responsibility to the patient in solving the problem;

3. The third aspect relates to the absurd and again unjust attribution of responsibility to "those who must work" and "not just to support" controlling the spread, without minimum working conditions, whether structural or human. Doctors and healthcare professionals, generically called the workforce and front-lines, have been neglected, exploited, humiliated, scrapped and devalued in the last 30 years! There's no need for "panels", "clapping" or "homage" to deliver the function they have always fulfilled, regardless of disrespect or lack of adequate resources for their livelihood. Not to mention, these workers when contaminated or sick, make it difficult to manage their condition, participating involuntarily in the transmission by going to work without testing, diagnosis and care.

Our epidemic companion, the virus, has no conscience, and doesn't even know what it's doing. Its survival is blind and programmed. It ignores all the technology, modern/expensive drugs produced by a selfish and profit-centered industry, who pressures and breaks the health system with ridiculous benefits and assumed damage. Those who are needed most at the moment show their inefficiency to act against a known - over 20 years - "little" agent, which is the cause of so many deaths and suffering.

The "mea culpa" has no use in proposing solutions, but it is fundamental because it establishes memory and responsibilities, alleviating the weight on a population that despite resilient is still vulnerable.

\section{WHAT ARE THE SOLUTIONS?}

1. Locate the "little guy" in individuals (at least symptomatic) and their contacts, individually isolating them;

2. Mapping and monitoring cases at the local level, and not at the national level, which is politically and mathematically pointless;

3. Appropriately assisting serious cases so that they feel cared for. Only then, can we attribute outcomes to the "little guy";

4. Investing in the ethical generation of centralized and multicentric scientific evidence, by restraining repeated and self-centered disaggregated efforts;

5. Taking advantage of the opportunity to educate the population, in an understanding and kind manner - at the same time rigorous and adamant - through the reinforcement of democratic thinking, where not everything is allowed when considering others;

6. Seeking equity in a fragmented and inequitable health system, using as a model the private assistance system; 
7. Finally, although we know that we're not in control of life, remember that everyone has a role in this process, including the virus. The latter, however, cannot be in control, and its high time that those with responsibility showed that they are the ones in control.

\section{REFERENCES}

1. Pan A, Liu L, Wang C, Guo H, Hao X, Wang Q, et al. Association of Public Health Interventions with the Epidemiology of the COVID-19 Outbreak in Wuhan, China. JAMA 2020 Apr 10. doi: 10.1001/jama.2020.6130. PMID: 32275295.

2. Wang C), Ng CY, Brook RH. Response to COVID-19 in Taiwan: Big Data Analytics, New Technology, and Proactive Testing. JAMA 2020. doi: 10.1001/ jama.2020.3151. PMID: 32125371.

3. Onder G, Rezza G, Brusaferro S. Case-Fatality Rate and Characteristics of Patients Dying in Relation to COVID-19 in Italy. JAMA. 2020. doi: 10.1001/ jama.2020.4683. PMID: 32203977.

4. Yen MY, Schwartz J, Chen SY, King CC, Yang GY, Hsueh PR. Interrupting COVID-19 transmission by implementing enhanced traffic control bundling: Implications for global prevention and control efforts. | Microbiol Immuno Infect 2020. doi: 10.1016/j.jmii.2020.03.011. PMID: 32205090.

5. Emanuel El, Persad G, Upshur R, Thome B, Parker M, Glickman A, et al. Fair Allocation of Scarce Medical Resources in the Time of Covid-19. N Eng | Med 2020. doi: 10.1056/NEJMsb2005114. PMID: 32202722

6. Wu Z, McGoogan JM. Characteristics of and Important Lessons From the Coronavirus Disease 2019 (COVID-19) Outbreak in China: Summary of a Report of 72314 Cases From the Chinese Center for Disease Control and Prevention. IAMA 2020. doi: 10.1001/jama.2020.2648. PMID: 32091533.

7. Ioannidis JPA. Coronavirus disease 2019: The harms of exaggerated information and non-evidence-based measures. Eur | Clin Invest. 2020; 50 e13222. doi: 10.1111/eci.13222. PMID: 32191341.

8. Boccia S, Ricciardi W, loannidis IPA. What Other Countries Can Learn From Italy During the COVID-19 Pandemic. JAMA Intern Med 2020. doi: 10.1001/ jamainternmed.2020.1447. PMID: 32259190.
Times passing by, and together the consequences may be - or already are - greater or lesser depending on future decisions.

It is critical to stop investing in a denial strategy, (which only aspires pity from those who know science), and prompt despair in those who don't.

9. Desjardins MR, Hohl A, Delmelle EM. Rapid surveillance of COVID-19 in the United States using a prospective space-time scan statistic: Detecting and evaluating emerging clusters. Appl Geogr 2020; 118: 102202. doi: 10.1016/j. apgeog.2020.102202. PMID: 32287518; PubMed.

10. Kim Y|, leong Y|, Kim SH, Kim Y|, Lee SY, Kim TY, et al. Preparedness for COVID-19 infection prevention in Korea: Single-center experience. J Hosp Infect 2020. pii: S0195-6701(20)30193-6. doi: 10.1016/j.jhin.2020.04.018. PMID: 32302723.

11. Shim E, Tariq A, Choi W, Lee $Y$, Chowell G. Transmission potential and severity of COVID-19 in South Korea. Int J Infect Dis. 2020; 93: 339-344. doi: 10.1016/j.ijid.2020.03.031. PMID: 32198088.

12. COVID-19 National Emergency Response Center, Epidemiology \& Case Man agement Team, Korea Centers for Disease Control \& Prevention. Contact Transmission of COVID-19 in South Korea: Novel Investigation Techniques for Tracing Contacts. Osong Public Health Res Perspect 2020; 11:60-63. doi: 10.24171/j.phrp.2020.11.1.09. PMID: 32149043.

13. Diretrizes AMB COVID-19. Disponível em URL: https://amb.org.br/ wp-content/uploads/2020/04/DIRETRIZES-AMB-COVID-19-atualizado-em 09.04.2020. pdf.

14. Chan JF, Yuan S, Kok KH, To KK, Chu H, Yang J, et. A familial cluster of pneumonia associated with the 2019 novel coronavirus indicating person-to-person transmission: a study of a family cluster. Lancet 2020; 395 : 514-523. doi: 10.1016/S0140-6736(20)30154-9. PMID: 31986261.

15. The Lancet. COVID-19 in the USA: a question of time. Lancet 2020; 395 : 1229. doi: 10.1016/S0140-6736(20)30863-1. PMID: 32305080 